\title{
Influence of 3D-printing Parameters on Mechanical Properties of PLA defined in the Static Bending Test
}

\author{
A. Kołodziej ${ }^{1}$, P. Żur ${ }^{1}$, A. Baier ${ }^{1}$ and W. Borek $^{1}$ \\ ${ }^{1}$ Silesian University of Technology, Faculty of Mechanical Engineering, \\ Konarskiego 18a, 44-100 Gliwice, Poland.
}

\section{ARTICLE INFO}

Keywords:

\begin{abstract}
The paper presents optimization of the weight of elements printed in Fused Deposition Modelling (FDM) technology. For this purpose, the static bending test was carried out. The test was carried out in compliance with PN-EN ISO 178:2011 standard. Samples were made of polylactide (PLA). The influence of such parameters as filling density and type of filling or its orientation was examined. The collected data allowed to calculate the maximum stresses in the material used to improve the Silesian Greenpower car. Compared infill patterns and their density allowed to choose the optimal printing method.
\end{abstract}

\section{Introduction}

Recent advances in the fields of Computer Aided Design (CAD) and Rapid Prototyping (RP) have given designers the tools to rapidly generate an initial prototype from a concept. Modern mechanical engineering frequently requires quick solutions - often rapid prototyping is the answer. Rapid manufacturing methods - such as Fused Deposition Modelling (FDM) habitually called 3D printing - have significantly developed in the past three decades. FDM uses layering of melted thermoplastic material. The method exploits a moving nozzle, which uses the so-called extruder to collect the filament, melt it and apply it to the printing table.

Most recently, the number of factors have made addictive manufacturing methods more available and commonly used. Rapid prototyping methods are gaining popularity in many industries mainly due to the multitude of their use. However different applications require different material properties and several printing parameters may affect the product's strength.

Silesian Greenpower team uses 3D printing to obtain elements of almost unrestricted shape at relatively low cost. Exemplary elements made in additive manufacturing technology are mirror housing (Fig. 1), back wheel fairing and fan holder. Reducing the weight of a whole vehicle is crucial in the whole automotive industry for both - electrical and traditional cars. The weight of the 3D-printed element can be reduced by changing infill type and it's density. 


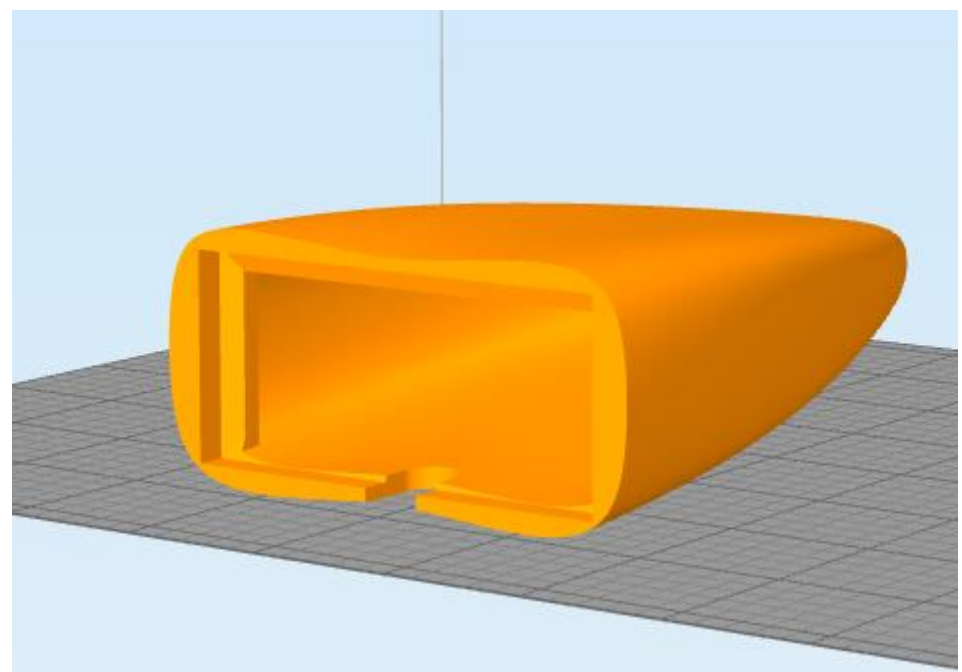

Fig. 1. Mirror housing 3D-printed by Silesian Greenpower team.

One of the most commonly used strength tests is the static bending test. Its widespread use results from the fact that the sample does not have a complicated shape, which makes it easy to fabricate, and the test is simple to carry out while giving ready to interpret results. Fatigue is considered as one of the main causes of structural failure of a material.

Purpose of this research is to find optimal printing parameters in order to reduce the weight of the printed object while maintaining the required mechanical properties. The following paper describes the influence of such parameters as infill density and type on the modulus of elasticity, maximum stress and deflection value.

2 Test objective

Test samples were made in compliance with PN-EN ISO 178:2011 International Standard. The material used to print specimens was PLA - polylactic acid - a thermoplastic, further classified as a polyester plastic. PLA is characterised by one of the highest heat capacity among the polyester plastics.

Due to new techniques which allow economical production of high molecular weight PLA, this polymer has attracted large attention recently being considered as one of the most promising materials for replacing synthetic polymers.

Physical and mechanical properties of PLA were represented in Table 1.

Table 1. Physical and mechanical properties of bulk PLA

\begin{tabular}{lll}
\hline Material property & Value & Units \\
\hline Density $(\rho)$ & 1.24 & $\mathrm{~g} / \mathrm{cm}^{3}$ \\
\hline Elastic modulus $(E)$ & 3500 & $\mathrm{MPa}$ \\
\hline Shear modulus $(G)$ & 1287 & $\mathrm{MPa}$ \\
\hline Poisson's ratio $(v)$ & 0.36 & - \\
\hline Yield strength $\left(\sigma_{y}\right)$ & 70 & $\mathrm{MPa}$ \\
\hline Flexural strength $\left(\tau_{z}\right)$ & 106 & $\mathrm{MPa}$ \\
\hline Elongation & $\sim 7$ & $\%$ \\
\hline
\end{tabular}

Recommended shape of the specimen, according to PN-EN ISO 178:2011 standard is a rectangle $80 \times 4 \times 10 \mathrm{~mm}$. Samples were modelled in Siemens NX, and prepared for 3D-printing in Slic3r 
software. Knowing that layer height of $0.1 \mathrm{~mm}$ provides a better connection of the outline with the infill, and of the infill itself than $0.3 \mathrm{~mm}$ layer. Furthermore, printing at $220^{\circ} \mathrm{C}$ temperature allows obtaining higher tensile strength than at $185^{\circ} \mathrm{C}$.

This property of an item - high tensile strength - is crucial for manufacturing high-quality and durable pieces for the Silesian Greenpower electric vehicle - e.g. mirror case. At higher printing temperature and lower layer height, the higher cooling rate influences fragility of the material lowers tensile strength significantly. At the rate of $100 \%$ cooling, the material is cooled down too rapidly whereby individual strokes did not connect enough with each other. To avoid fragility of the material, lower cooling rate $-50 \%$ is recommended.

Based on this knowledge, the following printing parameters have been set: printing temperature $220^{\circ} \mathrm{C}$, layer height $0.1 \mathrm{~mm}$ and cooling rate $50 \%$. Tested parameters are infill density and its type or orientation (depending on density), which have been described and presented in Table 2. Possible infill patterns are grid and honeycomb with different density, or a full infill (100\%) with different line orientation 45 or $90^{\circ}$.

Infill types have been presented in Fig. 2, while layer orientation type has been presented in Fig. 3. For each of the 8 categories of parameters 6 samples were made, which gave 48 specimens in total.

Table 2. Tested parameters

\begin{tabular}{lllllllll}
\hline Type & 1 & 2 & 3 & 4 & 5 & 6 & 7 & 8 \\
\hline $\begin{array}{l}\text { Infill } \\
\text { percentage [\%] }\end{array}$ & 10 & 25 & 50 & 10 & 25 & 50 & 100 & 100 \\
\hline $\begin{array}{l}\text { Infill pattern } \\
\text { Grid }\end{array}$ & Grid & Grid & $\begin{array}{l}\text { Honey- } \\
\text { comb }\end{array}$ & $\begin{array}{l}\text { Honey- } \\
\text { comb }\end{array}$ & $\begin{array}{l}\text { Honey- } \\
\text { comb }\end{array}$ & $\begin{array}{l}\text { Line } \\
\left(45^{\circ}\right)\end{array}$ & $\begin{array}{l}\text { Line } \\
\left(90^{\circ}\right)\end{array}$ \\
\hline
\end{tabular}

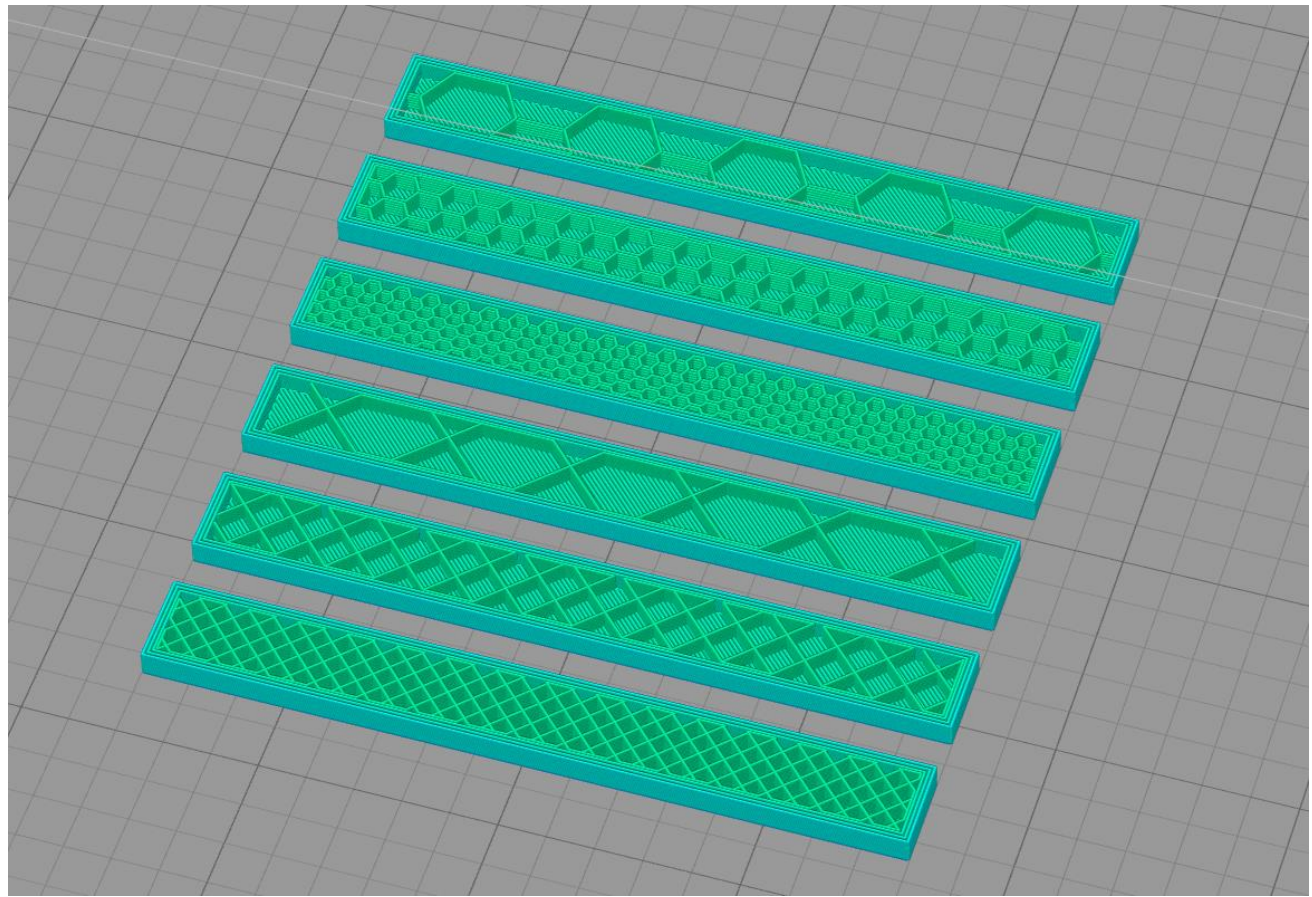

Fig. 2. Infill types from the top: honeycomb 10, 25 and 50\% and grid 10, 25 and 50\% infill. 


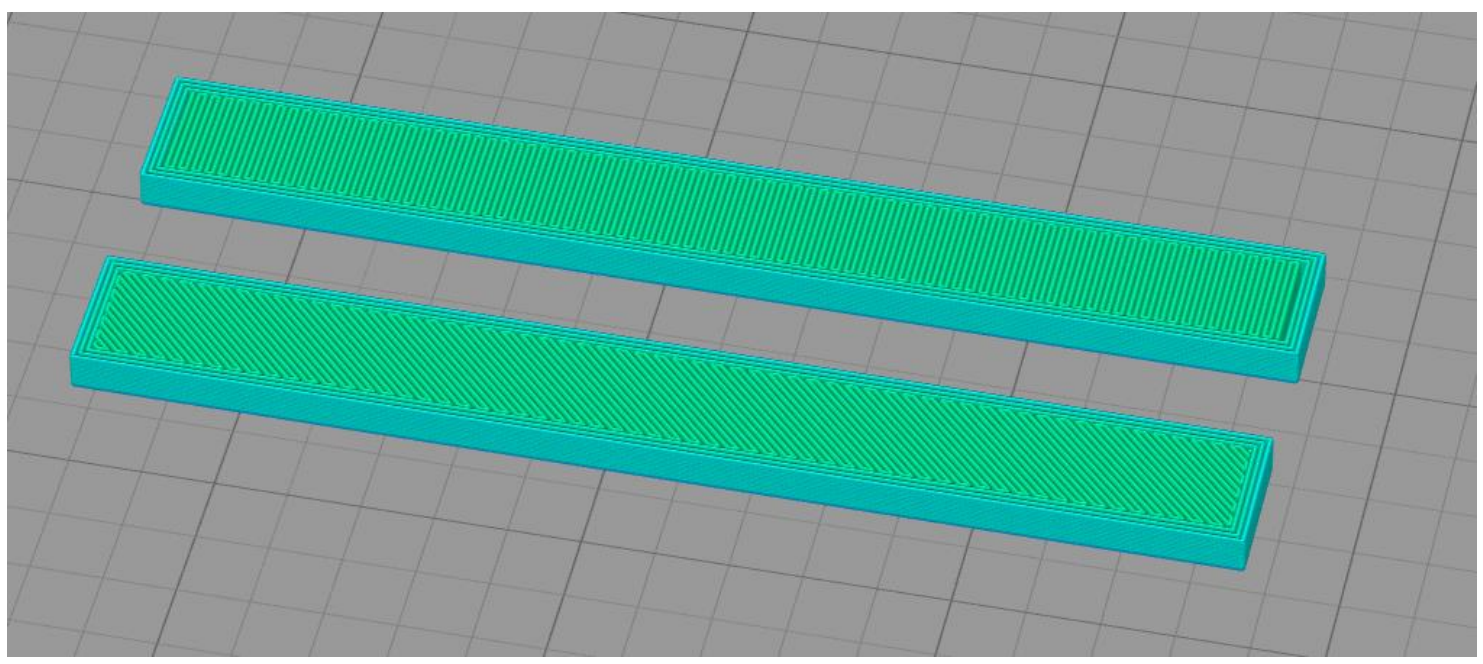

Fig. 3. Layer orientation at infill density $100 \%$ from the top: $90^{\circ}$ and $45^{\circ}$.

\section{Results and discussion}

The static bending test was carried out for each of 48 specimens. Average results for each series have been shown in Table 3. It can be seen, that highest modulus of elasticity and maximum stress represent series 1 (grid 10\%) - $1980 \mathrm{MPa}$ at the 46,7 stress.

On the contrary, highest value of modulus of elasticity and maximum stress represent, as expected - series with $100 \%$ infill density, series $7\left(100 \%\right.$ infill at $\left.45^{\circ}\right)$ and series $8\left(100 \%\right.$ infill at $\left.90^{\circ}\right)-$ their modulus of elasticity is above $3000 \mathrm{MPa}$, which is over $1000 \mathrm{MPa}$ more than the lowest value obtained in the test respectively 3149 and $3028 \mathrm{MPa}$.

Moreover, the percentage relative deviation for both of these series is below $2 \%$ value, which means results for each specimen of the series were repeatable. The average value of modulus of elasticity in the test is $2380 \mathrm{MPa}$, which is $68 \%$ of a modulus of bulk PLA value - it can be seen, that 3D-printed elements are characterized by lower tensile strength due to its heterogeneous structure - in this case layers of different patterns. 
Table 3. Average results in static bending test for each of 8 series.

\begin{tabular}{|c|c|c|c|c|c|c|c|c|c|c|c|c|}
\hline & \multicolumn{3}{|c|}{$\begin{array}{l}\text { Modulus of elasticity } \\
E_{\mathrm{f}}[\mathrm{Mpa}]\end{array}$} & \multicolumn{3}{|c|}{$\begin{array}{l}\text { Maximum stress } \\
\sigma_{\mathrm{fm}}[\mathrm{MPa}]\end{array}$} & \multicolumn{2}{|c|}{$\begin{array}{l}\text { Deflection } \\
\varepsilon_{\mathrm{fm}}[\mathrm{mm}]\end{array}$} & \multicolumn{4}{|c|}{$\begin{array}{l}\text { Offset yield point } \\
\sigma_{0,2}[\mathrm{MPa}]\end{array}$} \\
\hline & $\bar{x}^{\mathrm{a}}$ & $s^{\mathrm{b}}$ & $v^{\mathrm{c}}$ & $\bar{x}$ & $s$ & $v$ & $\bar{x}$ & $s$ & $v$ & $\bar{x}$ & $s$ & $v$ \\
\hline 1 & 1980 & 68 & 3,45 & 46,7 & 1,49 & 3,18 & 5,53 & 0,24 & 4,31 & 41 & 1,91 & 4,67 \\
\hline 2 & 2022 & 61 & 3,02 & 48,5 & 0,96 & 1,98 & 5,66 & 0,24 & 4,13 & 43 & 1,41 & 3,27 \\
\hline 3 & 2271 & 109 & 4,78 & 54,9 & 1,83 & 3,33 & 6,51 & 0,17 & 2,66 & 47 & 2,59 & 5,45 \\
\hline 4 & 2060 & 124 & 6,04 & 44,9 & 2,48 & 5,53 & 4,92 & 0,31 & 6,29 & 41 & 1,82 & 4,46 \\
\hline 5 & 2041 & 142 & 6,96 & 51,3 & 2,04 & 3,98 & 5,78 & 0,40 & 6,99 & 47 & 1,00 & 2,12 \\
\hline 6 & 2492 & 125 & 5,01 & 62,2 & 0,87 & 1,39 & 6,05 & 0,15 & 2,42 & 55 & 1,56 & 2,81 \\
\hline 7 & 3149 & 61 & 1,95 & 88,1 & 0,90 & 1,02 & 7,12 & 0,19 & 2,62 & 77 & 2,47 & 3,21 \\
\hline 8 & 3028 & 39 & 1,27 & 74,4 & 2,60 & 3,50 & 5,35 & 0,26 & 4,78 & 66 & 2,30 & 3,51 \\
\hline
\end{tabular}

${ }^{a}$ Arithmetic average.

${ }^{\mathrm{b}}$ Standard deviation.

'Percentage relative deviation.

The highest deflection value at the breakpoint has been noticed for series $7-7,12 \mathrm{~mm}$ and series 3 (grid 50\%) - 6,51 mm, while the lowest for series 4 (honeycomb 10\%) - 4,92 mm.

Surprisingly, deflection value for series 8 is not as high as for series 7 , although both series had $100 \%$ infill density - layer orientation at $45^{\circ}$ improves the strength of an element. Force-deflection graph of the series 7 has been shown in Fig. 4 .

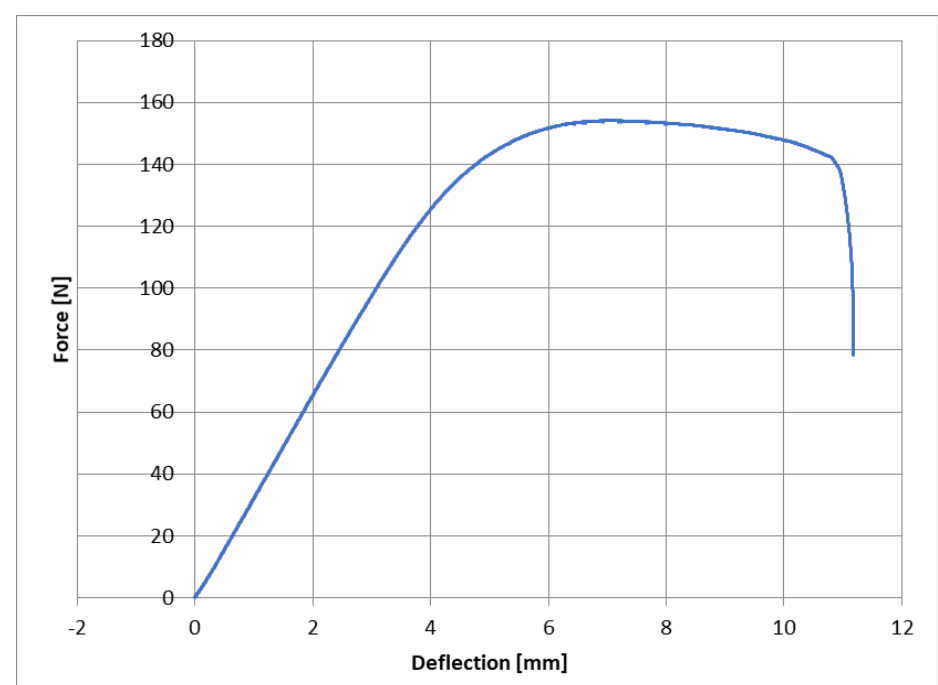

Fig. 4. Force-deflection graph for the most durable printing method (series 7: infill 100\% with layer orientation 45 degrees).

Although series 7 and 8 represent highest values, fact that both have $100 \%$ infill density make them harder to produce - more time and material is needed for the manufacturing of items, which not necessarily need such high modulus of elasticity or maximum stress. 
Tests have shown that the strength of the print with honeycomb infill with a density of $25 \%$ is equal to a grid pattern with $50 \%$ infill. Influence of these infill patterns have been shown in Table 4.This allowed reducing the printing time of one of the mirror housing (Fig. 1) used in the Silesian Greenpower car by 28 minutes.

The most important advantage of changing the filling method was to reduce weight by almost $30 \%$. Additionally, the cost of manufacturing the element was reduced - from 1,67 $€$ per element to $1,18 €$.

Table 4. Influence of infill type on cost and production time of mirror housing

\begin{tabular}{lll}
\hline Infill precentage & Grid (50\%) & Honeycomb $(25 \%)$ \\
\hline Build time & 218 minutes & 190 minutes \\
\hline Plastic weight & $79,65 \mathrm{~g}$ & $56,28 \mathrm{~g}$ \\
\hline Material cost & $1,67 €$ & $1,18 €$ \\
\hline
\end{tabular}

\section{Conclusions}

1. Increase of infill density improves modulus of elasticity and maximum stress values.

2. Full infill (100\%) allows to obtain the highest value.

3. Layer orientation at $100 \%$ infill does have an impact on strength of the specimen -45 degree layered specimen represents higher value than 90 degree one.

4. Infill pattern influences the strength of the sample $-25 \%$ honeycomb infill has similar modulus of elasticity and maximum stress values as $50 \%$ grid infill pattern.

5. Infill density does have an impact on deflection value - the higher the infill density the higher deflection value

\section{Acknowledgements}

We would like to acknowledge the support provided by Ph.D. Wojciech Borek from Institute of Engineering Materials and Biomaterials with realization of the static bending test and providing the results. 


\section{References}

makeitfrom.com [retrieved 03-11-2018]

Loncierz, D., \& Kajzer, W. (2016). Wpływ parametrów druku 3D w technologii FDM na własności mechaniczne i użytkowe obiektów wykonanych z PLA. Aktualne Problemy Biomechaniki, (10), 4348.

PN-EN ISO 178:2011 Plastics - determination of flexural properties

Torres, J., Cotelo, J., Karl, J., \& Gordon, A. P. (2015). Mechanical property optimization of FDM PLA in shear with multiple objectives. Jom, 67(5), 1183-1193.

matweb.com [retrieved 03-11-2018]

Baier, A., Zur, P., Kolodziej, A., Konopka, P., \& Komander, M. (2018, August). Studies on optimization of 3D-printed elements applied in Silesian Greenpower vehicle. In IOP Conference Series: Materials Science and Engineering (Vol. 400, No. 2, p. 022010). IOP Publishing.

Karasiewicz, T., Moraczewski, K., Rytlewski, P., Stepczyńska, M., \& Żenkiewicz, M. (2012) Metody badań $i$ oceny niektórych właściwości tworzyw polimerowych i metali. ISBN 978-837096-858-8

Żenkiewicz, M., Rytlewski, P., \& Malinowski, R. (2010). Compositional, physical and chemical modification of polylactide. Journal of Achievements in Materials and Manufacturing Engineering, 43(1), 192-199.

O. Kenzo, I. Tomokazu, Y. Tadashi, Y. Masayuki, Miscibility, mechanical and thermal properties of poly(lactic acid)/polyester-diol blends, European Polymer Journal 48 (2009) 2304-2312.

Montero, M., Roundy, S., Odell, D., Ahn, S. H., \& Wright, P. K. (2001). Material characterization of fused deposition modeling (FDM) ABS by designed experiments. Society of Manufacturing Engineers, 10(13552540210441166).

Grandini, S., Goracci, C., Monticelli, F., Tay, F. R., \& Ferrari, M. (2005). Fatigue resistance and structural characteristics of fiber posts: three-point bending test and SEM evaluation. Dental Materials, 21(2), 75-82. 